\section{Landsat to be bailed out?}

\section{Washington}

THE US National Space Council headed by Vice-President Dan Quayle will recommend this week that President George Bush bail out the troubled Landsat satellite remote-sensing programme. The councilwhose membership includes administration budget officials - voted unanimously last week to give EOSAT, the private company that operates the Landsat satellites, $\$ 5$ million to keep Landsats 4 and 5 running until the end of the year, and $\$ 20$ million to subsidize running costs for 1990.

The Landsat programme was nearly cancelled two months ago when the US National Oceanic and Atmospheric Administration (NOAA) ordered EOSAT to shut down the Landsat 4 and 5 satellites because there was no money to operate them. But without the Landsats, the United States would be forced to buy all non-defence satellite images from the French SPOT programme, and the Space Council came up with temporary funding that permitted NOAA to rescind its shutdown order two weeks after it was issued (see Nature 338, 365; 1989).

The $\$ 5$ million to be provided by the space council will come from the budgets of other government agencies that use the satellite images, such as the Department of Agriculture. Next year's budget is still being debated by Congress, but the $\$ 20$ million for 1990 is expected to be included in a budget amendment to be proposed by the administration.

The council also agreed last week that the launch of the new Landsat 6, scheduled for 1991, should proceed as planned. Under the agreement with EOSAT, NOAA pays for the development and launching of new satellites, but it now may have to take on part of the operating costs as well.

NOAA spun off management of the Landsat programme to EOSAT in 1985 in the hopes it would become a profit-making operation.

Although the government made a commitment to provide the operating costs of the two existing Landsat satellites, both have now exceeded their design lives, placing a burden on NOAA's perennially stretched budget.

The space council decision has been interpreted as an implicit admission by the administration that remote-sensing enterprises cannot be run as private companies that are expected to make a profit. The council is expected to recommend that President Bush make a "long-term commitment" to the Landsats, which may involve a reorganization of how the entire programme is managed. NOAA will continue to oversee the Landsats for the nearterm, but that may change as a result of further deliberations.

Carol Ezzell

\title{
US-Japanese row continues
}

\section{Tokyo}

WHEN Ken Sakamura of Tokyo University set out in 1985 to redesign fundamentally the architecture of computers - both hardware and software - his dream was a new standard that would allow computers of all shapes and sizes to talk to one another throughout the world. Last week, that dream came down to earth as Sakamura took battle with the US trade representative, Carla Hills, who sees his independently developed computer system as a barrier to the sale of US products in Japan (see Nature 339, 88; 11 May 1989).

In a letter sent to Hills last week, Sakamura demands that all references to his TRON (The Real-time Operatingsystem Nucleus) project be removed from the 1989 National Trade Estimate Report on Foreign Trade Barriers. The report will be used to designate 'priority countries' for possible US trade sanctions by the end of this month.

The US trade office claims that the Center for Educational Computing (CEC), a foundation set up by Japan's Ministry of Education, Science and Culture (MESC) and the Ministry of International Trade and Industry (MITI) to select computers for high schools, has laid down specifications for the operating system of the computers that are favourable to TRON. And the US trade office fears that operating systems developed by US companies (such as MS-DOS and UNIX) will be shut out of MESC's lucrative $\$ 6,900$-million procurement of computers for Japan's schools.

Sakamura strongly denies these claims. Twelve companies have submitted experimental machines to CEC that use a TRON operating system. But the CEC specifications do not mention TRON. And the experimental computer submitted by NEC Corporation of Japan can operate on MS-DOS as well as a TRON operating system, according to Sakamura in his letter to Hills.

Japanese subsidiaries of the US companies IBM and Unisys Ltd. are among those which have submitted experimental machines to CEC, and CEC's hardware specifications match those of an IBM personal computer with a 16-bit microprocessor made by the US company Intel. Sakamura thus says that the US trade office's contention that "no US manufacturer is in a position to sell TRON-based personal computers" is "incorrect". And he adds that he made the basic design of TRON architecture freely available to all companies, Japanese and foreign alike, to prevent the development of "proprietary" (and incompatible) technology.

Sakamura openly admits he is a "dreamer". And some of his ideas do seem to verge on fantasy. A promotion video for TRON declares that in the TRON "intelligent house" of the future TRON sensors embedded in the walls will open and shut the windows like a "king's servant" to create the kind of natural breeze that human beings like. And in "TRON City", microprocessors in the road will automatically detect a child running into the street and command TRON cars to grind to a halt and avoid collision.

But such is the way to promote new technology in Japan and the huge consortium of companies that are now backing TRON have their feet firmly planted on the ground. Following a decision by Motorola and Intel of the United States not to license their latest 32-bit microprocessors to Japanese companies, three Japanese electronics giants - Hitachi, Fujitsu, and Mitsubishi Electric - banded together in 1987 to develop 32-bit TRON microprocessors. Membership of the TRON Association, a grouping of companies set up last year to promote TRON, has swelled to 125 , including Motorola, Intel and more than 20 other European and US companies.

According to TRON advocates, the 32bit microprocessors from Motorola and Intel are like old factories with extensions built on - their ability to process data is slowed down by their need to maintain compatibility with old technology. But TRON 32-bit microprocessors, samples of which are now available, have been developed hand-in-hand with their operating systems.

TRON operating systems are also designed to handle the Chinese characters (kanji) of the Japanese language. It takes twice as many bits per character to encode the thousands of kanji in Japanese as it does to encode roman letters or numbers. And until recently, personal computers have not been particularly adept at Japanese word processing.

But will TRON penetrate the world market? In the United States and Europe, where there is already a considerable infrastructure of computer hardware and software, it seems unlikely that users will rip out and replace their present systems. But some of the TRON 32-bit microprocessors soon to be launched on the market are compatible with the widely used UNIX operating system developed by AT\&T.

It is in Japan that TRON has the best chance of making inroads. Personal computers are conspicuous by their absence in Japanese offices, homes and schools. Computer networks are also in their infancy. There is thus an open and waiting market when the first commercial TRON computers come available in 1990.

David Swinbanks 